\title{
Development of Test Vessel for Gas Insulation Breakdown Test
}

\author{
Ayuamira Zahari ${ }^{1}$, Hidayat Zainuddin ${ }^{2}$, Muhammad Saufi Kamarudin ${ }^{3}$, Nur Farhani Ambo ${ }^{4}$, \\ Jamaludin Mohd Wari ${ }^{5}$, Imran Sutan Chairul ${ }^{6}$ \\ ${ }^{1,2,4,6}$ High Voltage Engineering Research Laboratory, Faculty of Electrical Engineering, Universiti Teknikal Malaysia \\ Melaka, Malaysia \\ ${ }^{3}$ Faculty of Electrical and Electronic Engineering, Universiti Tun Hussein Onn, Malaysia \\ ${ }^{5}$ Indkom Engineering Sdn. Bhd., Malaysia
}

\begin{tabular}{l}
\hline \hline Article Info \\
\hline Article history: \\
Received Dec 21, 2017 \\
Revised Jan 22, 2018 \\
Accepted Feb 7, 2018
\end{tabular}

Keyword:

Air breakdown

Gas insulation

High voltage

Sulphur hexafluoride

Test vessel

\begin{abstract}
This paper discusses a new test vessel developed to investigate the breakdown test performance of gas insulation. The test vessel is equipped with certain specialty including pressure chamber and control measures. Through help from a steering, it is provide of controlling the gap length of the electrodes without the need of removing the gas. Other control measures include humidity, temperature, and pressure readings. The humidity and temperature are read wirelessly and from the readings, the necessary atmospheric corrections can be made according to standards. The developed vessel is then tested with $\mathrm{AC}$ breakdown test using air with various gap lengths and various electrode configurations. There are two types of electrode configuration used in this project i.e., rod (R0.5)-plane and planeplane.
\end{abstract}

Copyright $\odot 2018$ Institute of Advanced Engineering and Science. All rights reserved.

\section{Corresponding Author:}

Hidayat Zainuddin,

High Voltage Engineering Research Laboratory, Faculty of Electrical Engineering,

Universiti Teknikal Malaysia Melaka,

Hang Tuah Jaya, 76100 Durian Tunggal, Melaka, Malaysia.

Email: hidayat@utem.edu.my

\section{INTRODUCTION}

In high voltage engineering applications, the simplest and the most commonly found dielectrics are gases. The main purpose of dielectric gas is to restrain electrical discharges. A good dielectric gas should have high dielectric strength, good heat transfer properties, chemical inertness against the construction materials used, non-flammability, low toxicity, low boiling point, and low cost [1]. Sulphur hexafluoride $\left(\mathrm{SF}_{6}\right)$ gas has been found to possess most of these properties (i.e. have a dielectric strength three times higher than air, chemically inert and stable, high arc interruption capability, non-toxic, and non-flammable) which, until now, make it dominating in most of the high voltage applications such as in the gas-insulated transmission line (GIL), gas-insulated switchgear (GIS), and gas circuit breaker (GCB) [2]. Due to its domination, the necessity to improve the diagnostic technique for current assets that used $\mathrm{SF}_{6}$ as insulant is vital and a recent work has been reported elsewhere [3].

However, $\mathrm{SF}_{6}$ gas was classified as harmful gases. It was listed as one of the six greenhouse gases in Kyoto Protocol 1997 and has the highest global warming potential (GWP) among other gases [4]. Until recently, researchers have been trying to find suitable alternative gas mixtures to minimize its usage in high voltage applications, experimentally [5, 6] and through simulation model [7]. For experimental work, a reliable pressurized vessel that is suitable for high voltage applications and able to withstand high pressure is required. It is worthwhile noting that, until recently no standard is available to provide the design of test vessel for gas insulation breakdown test. Various designs of test vessel have been used by other researchers $[8,9]$. Hence, this paper will explain in details on the construction of a test vessel for this application. A test vessel for carrying out the experimental works on insulation gas testing will be explained. 


\section{DESIGN OF THE TEST VESSEL}

\subsection{Structure}

Figure 1 shows the initial drawing for the desired structure of the test vessel. The test vessel consists of three main parts; top, bottom and side windows. The height of the test vessel is $700 \mathrm{~mm}$ with a radius of $30.56 \mathrm{~mm}$, giving the volume of the test vessel around $0.205 \mathrm{~m}^{3}$, or 205 liters. In addition, the thickness of the test vessel is $20 \mathrm{~mm}$ minimum. This thickness applies everywhere; on top, bottom, and also the side walls of the test vessel.

At the top part of the test vessel, there is a room to place a high voltage bushing. The conductor in the bushing is then connected to a high voltage source. The main function of the bushing is to allow an electrical conductor to pass safely through a grounded conducting barrier.

Next, the side windows are indispensable in order to show every process that occurs in the vessel while the gas mixtures are being tested. These windows will also help the researcher to adjust and validate the gap distance between the high voltage electrode and the ground electrode as required for each testing. Besides, purification process of the vessel after completing each test or if necessary is also easier with these side windows. In order to increase the reliability of this vessel, O-rings are used to prevent any leakage at every point which has bolts and nuts. These O-rings are also located at both side windows.

The bottom part of the vessel is mounted with a steering to manually control the vertical position of ground electrode. This is important to vary the gap length between the high voltage electrode and the ground electrode without the need of removing the gas. The gap length will be displayed by the digital vernier caliper with $0.01 \mathrm{~mm}$ resolution.

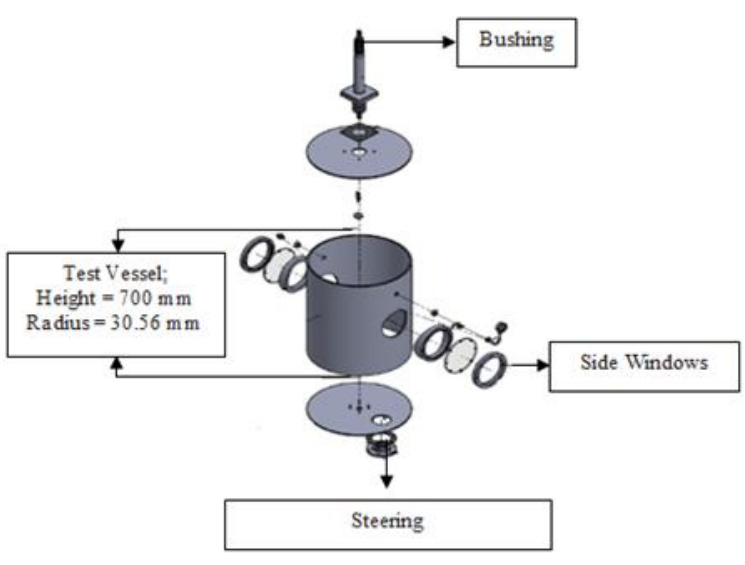

Figure 1. Test vessel initial design

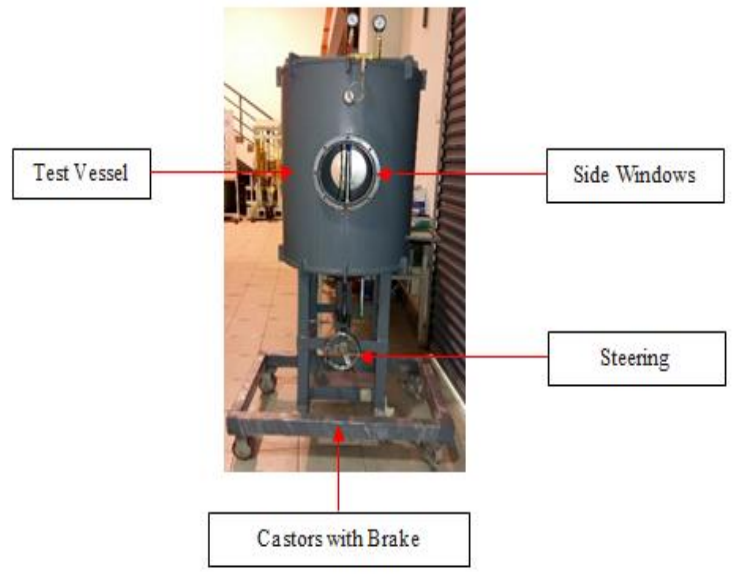

Figure 2. Complete structure of the test vessel

Figure 2 shows the complete structure of the test vessel. The test vessel is welded with four steelangled legs. The legs are joined together at the bottom with four castors and each castor is fitted with a brake for safety reasons. The minimum height of the structure from the floor is $820 \mathrm{~mm}$. This is to ensure enough clearance for all the fittings and assemblies. As mentioned earlier, the side windows are equipped with O-rings to prevent or minimize any gas leakage. This O-ring is made from rubber where it is very elastic and also the most common seals used in machine design since it is inexpensive, easy to make, reliable and having simple mounting requirements. Moreover, it is also can seal thousands of psi of pressure.

\subsection{Material}

The materials of the test vessel shall follow industrial standard to ensure that the structure can withstand high voltage stress with a specific high pressure. For this test vessel, the design and structure were built after having a discussion with a switchgear company manufacturer; Indkom Engineering Sdn. Bhd. For this reason, mild steel with code SECC-P, is chosen as the material for the structure. The test vessel is also painted with a normal steel paint or metal coating for corrosion protection.

The side window is made of polycarbonate, a type of thermoplastic which is very tough and that is used in many applications [10]. The thickness of the polycarbonate used for the window is $20 \mathrm{~mm}$. This thickness is capable to withstand a pressure of more than 5 bar. To note, this pressure level is very high compared to the pressure that will be used in our future work, i.e. up to 1.5 bar. Although it seems quite 
thick, the visibility inside the vessel is very clear. Polycarbonate is also a type of a bulletproof material which can withstand for tensile strength up to $90 \mathrm{MPa}$.

\subsection{Fitting and assemblies}

A number of fittings and assemblies are needed in order to complete the test vessel. This section explains all the necessary equipment fittings.

\subsubsection{Electrodes}

The electrodes as shown in Figure 3 are made from brass which is an alloy made from copper $(\mathrm{Cu})$ and zinc $(\mathrm{Zn})$. There are three different geometries which are available for the tests; plane (R100, R48), hemisphere (R24), and rod (R0.5, R6, R12). To note, the alphabet "R" is referring to the radius of the tip of the corresponding electrode in millimeter $(\mathrm{mm})$ unit. For example, rod (R0.5) is having a tip radius of 0.5 $\mathrm{mm}$. In this test vessel, all the high voltage electrodes which are connected to the bushing are stationary while the ground electrodes on the other hand, are vertically moveable so that a desired gap length between both electrodes can be achieved using a wheel manual handling.

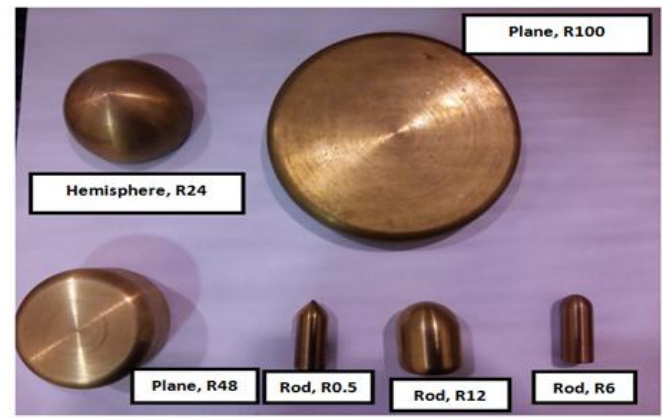

Figure 3. Electrodes

\subsubsection{Steering}

The gap length between high voltage electrodes and ground electrodes can be controlled and varied using steering as shown in Figure 4. With this ability, the effects of gap lengths on the breakdown test can be examined while maintaining other tests parameters, such as gas mixtures ratio, gas pressures and electrode configuration. The maximum gap length that can be achieved is up to $200 \mathrm{~mm}$ height. As a precaution, rubber seal has been used at certain points to avoid gas leaking when operating the steering.

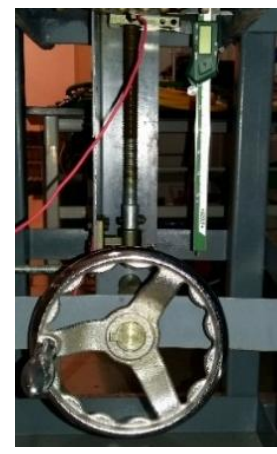

Figure 4. Steering

\subsubsection{Bushing}

A bushing is needed so that the high voltage stress can be passed through to an electrode inside the vessel without any risk of flashover to the vessel body. Figure 5 below shows the bushing used in this project. The bushing conductor is made from copper and it is bonded to a silicone rubber jacket as an outside housing insulator. The specifications of the bushing are shown in Table 1. With the stated specifications, the 
bushing is suitable for a $38 \mathrm{kV}$ rated system [11].



Figure 5.Bushing

Table 1. Bushing specifications

\begin{tabular}{ll}
\hline AC Dry Power Frequency & $70 \mathrm{kV} / \mathrm{min}$ \\
Lightning Impulse & $170 \mathrm{kV} \mathrm{BIL}$ \\
SF6 Gas Tightness & No leaks
\end{tabular}

SF6 Gas Tightness $\quad$ No leaks

\subsubsection{Hose, Valves and Gauges}

Two types of gauges are used in this experimental setup for measuring pressure of less than 1 bar (vacuum condition) and more than 1 bar (pressurized state). In order to connect the gas cylinders to the vessel, a good quality of vacuum hose is needed to ensure there will be no leakage of gas anywhere along the hose. The vacuum hose is used along with the hose and ball valves tails. The ball valves will ensure the vacuum and pressurized states are locked properly.

\section{AC BREAKDOWN TEST}

In order to appraise the authenticity of the development of test vessel, a few experimental works on air subjected to AC breakdown test have been conducted. The test procedure of this test is complying with BS EN 60060-1:2010 standard [12].

Figure 6 shows the AC breakdown voltage of air for two different electrode configurations (i.e. plane-plane and R0.5-plane) with various gap distances (i.e. $10-50 \mathrm{~mm}$ ) before atmospheric correction. Throughout the test, the air pressure inside the vessel is fixed at $1 \mathrm{~atm} \approx 1 \mathrm{bar}$. The results shown are the mean values of 50 test data, $U_{\text {mean }}$. For a disruptive discharge voltage like AC breakdown voltage the mean value is identical to $50 \%$ probability of prospective voltage value that produces a disruptive discharge on the test object, $\mathrm{U}_{50}$ [12]. This is due to the fact that in most cases symmetric distribution of disruptive discharge voltage is determined.

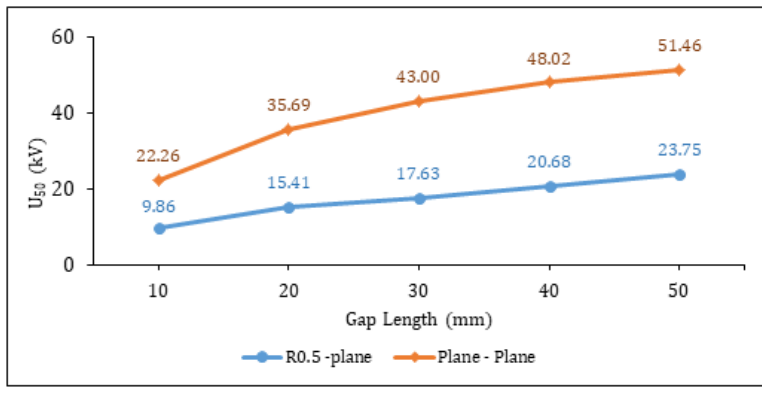

Figure 6. Mean ר value for air breakdown voltage tests

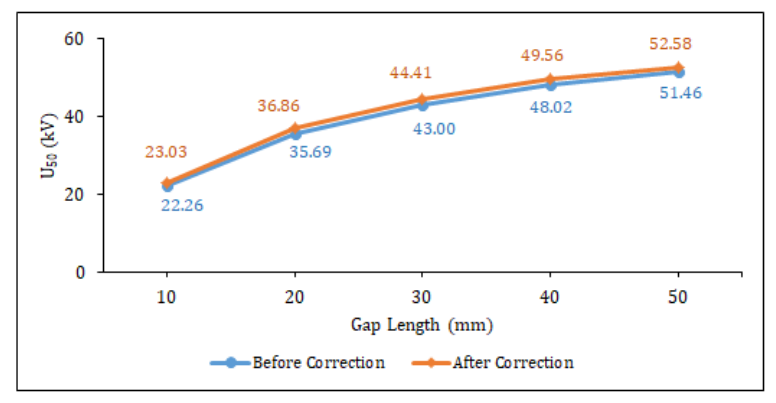

Figure 7. Mean value of plane-plane before and after correction 
As depicted in Figure 6, the average breakdown voltages of plane-plane and R0.5-plane configurations increase almost linearly with the gap length, from $10 \mathrm{~mm}$ up to $50 \mathrm{~mm}$. From this result, it can be concluded that the $\mathrm{U}_{50}$ value are affected by the gap length.

Besides that, different types of electrode configuration were also found to be affecting the breakdown voltage in which the plane-plane configuration had higher breakdown voltage compared to R0.5plane electrode configuration. This was due to the uniformity of electric field of electrode configuration. As the uniformity of electric field distribution increases (plane-plane), the breakdown voltage also increases.

In general, the breakdown voltage of air insulation will increase when the gap length of an electrode configuration increases. However, in real life, besides the dependency on the gap length, the breakdown of air insulation also depends on the atmospheric condition whereby an increase in the relative air density and relative humidity usually lead to the increase in the breakdown of air insulation. In specific, when the relative humidity exceeds $80 \%$, the breakdown voltage may become irregular. Hence, it is important to apply atmospheric correction factor, $\mathrm{K}_{\mathrm{t}}$ in order to obtain a more reliable value of air breakdown. Figure 7 shows the corrected value of breakdown voltages for plane-plane configuration.

Basically, the breakdown voltage of air is proportional to the atmospheric correction factor, $\mathrm{K}_{\mathrm{t}}$. In order to obtain the corrected value, a measured breakdown voltage, $\mathrm{U}$ in a given test conditions under certain temperature, pressure, and humidity, is then converted to the $\mathrm{U}_{50}$ value which would have been obtained under standard atmospheric conditions with a relation of $U_{50}$ (after corrected) $=U / K_{t}$. The atmospheric correction factor, $\mathrm{K}_{\mathrm{t}}$ actually proportional to the breakdown voltage; $\mathrm{K}_{\mathrm{t}}=\mathrm{k}_{1} \mathrm{k}_{2}$ where $\mathrm{k}_{1}$ is the air density correction factor while $\mathrm{k}_{2}$ is the humidity correction factor. The air density correction factor depends on the relative air density $\delta$ and can be expressed as $\mathrm{k}_{1}=\delta_{\mathrm{m}}$

\section{CONCLUSION}

A new test vessel has been developed specifically for gas research. There are two major parts in the test vessel development; design and structure of the test vessel, as well as a control unit (i.e. pressure gauges and electrode gap length control system). The electrode gap length control system is made possible by using a sealing gland without having to remove the gas from inside the test chamber, which greatly saves a lot of time. As it is important to investigate gas breakdown behavior in various electric fields, there is a need to use different kinds of electrode configurations. For that reason, a set of brass electrodes has also been obtained.

Based on the results obtained earlier on AC breakdown test of air at atmospheric pressure, it can be seen that the breakdown voltage and the gap length of the electrode have a linear relationship. Furthermore, the uniformity of the electrode configuration is also affects the breakdown voltage of the air breakdown. Fundamental tests on air breakdown have been carried out to investigate the $\mathrm{U}_{50}$ behavior of air in various test conditions. The results are corrected according to the correction factors defined by the standard in BS EN 60060-1 (2010) to ensure the accuracy.

\section{ACKNOWLEDGEMENTS}

The authors wish to thanks for the encouragement and financial assistance of Universiti Teknikal Malaysia Melaka and Ministry of Higher Education, Malaysia for the approved grant FRGS/1/2016/TK04/FKE-CERIA/F00304.

\section{REFERENCES}

[1] T. Takuma, O. Yamamoto and S. Hamada, "Gases as a Dielectric", Gaseous Dielectrics X, pp. 195-204, 2004.

[2] L. G. Christophorou, J. K. Olthoff, D. S. Green, U. S. G. P. Office, and E. D. and P. M. Division, "Gases for Electrical Insulation and Arc Interruption: Possible Present and Future Alternatives to pure SF6", National Institute of Standards and Technology, 1997.

[3] V. M. Ibrahim, Z. A. Malek and N. A. Muhamad, "Chemical By-Product Diagnostic Technique for Gas Insulated Switchgear Condition Monitoring”, Indonesian Journal of Electrical Engineering and Computer Science (IJEECS), vol. 7, no. 1, pp. 18-28, 2017.

[4] IPCC Core Writing Team, Working Group 1: The Physical Science Basis, "Errata of IPCC Fourth Assessment Report: Climate Change 2007”, 2012.

[5] M. S. Kamarudin et al., "Pressurized $\mathrm{CF}_{3} \mathrm{I}_{-} \mathrm{CO}_{2}$ Gas Mixture under Lightning Impulse and its Solid By-Products", International Journal of Electrical and Computer Engineering (IJECE), vol. 7, no. 6, pp. 3088-3094, 2017.

[6] M. S. Kamarudin, M. Albano, P. Coventry, N. Harid, and a. Haddad, "A survey on the potential of CF3I gas as an alternative for SF6 in high voltage applications", in 45th International Universities Power Engineering Conference (UPEC 2010., pp. 1-5, 2010.

[7] F. Hao and Z. Junmin, "Temperature Rise Comparison of Switchgear in SF6, N2, and Air", TELKOMNIKA Indonesian Journal of Electrical Engineering, vol. 11, no. 3, pp. 1377-1382, 2013. 
[8] M. S. Kamarudin, H. Zainuddin, A. Haddad, N. H. Radzi, A. Ponniran, and A. Zahari, "Purpose-Built Test Rig for Gas Insulation Breakdown Tests under Lightning Impulse", International Conference on Power and Energy (PECON), pp. 333-337, 2016.

[9] J.Ma, Q.Zhang, "Study on Insulation Characteristic of GIS under Combined Voltage of DC and Lightning Impulse", IEEE Trans. Dielectr. Electr. Insul., vol. 24, no. 2, pp. 893-900, 2017.

[10] PlasticsEurope, "The Plastic Portal - Polycarbonate", 2010. [Online]. Available: http://www.plasticseurope.org/what-is-plastic/types-of plastics/polycarbonate.aspx. [Accessed: 17-Jun-2013].

[11] International Electrotechnical Commission, "IEC 60137 - Insulated Bushing for Alternating Voltages Above 1000 V", 2003.

[12] European Committe for Electrotechnical Standardization, "BS EN 60060-1 : 2010 BSI Standards Publication Highvoltage Test Techniques Part 1 : General Definitions and Test Requirements", 2010.

\section{BIOGRAPHIES OF AUTHORS}


Ayuamira Zahari received her Bachelor's degree in Electrical Engineering (Control, Instrumentation and Automation) from Universiti Teknikal Malaysian Melaka (UTeM) in 2014. She is currently pursuing her MSc in Electrical Engineering at UTeM. Her research focus mainly on high voltage gas insulation.

Hidayat Zainuddin received his Bachelor's degree in Electrical Engineering from Universiti Teknologi Malaysia in 2003. He then obtained his Master of Science degree in Electrical Power Engineering with Business from University of Strathclyde, Glasgow, in 2005. He received his Ph.D degree from University of Southampton in 2013. He has served as an academic staff at Universiti Teknikal Malaysia Melaka (UTeM) since 2003 and he is currently an Associate Professor and Deputy Dean (Student Development) in the Faculty of Electrical Engineering, UTeM. He is also the Head of the High Voltage Engineering Research Laboratory (HVER Lab), UTeM. He was the Manager of Centre of Excellence for Robotics and Industrial Automation (CeRIA) at UTeM from 2014 to 2016. His research interests include green technology in high voltage system, high voltage equipment and insulation condition monitoring, failure analysis, and power system protection coordination.

Muhammad Saufi Kamarudin received his PhD Degree in High Voltage Engineering from Cardiff University, UK in 2014. He received his M.Sc. in Electrical Power Engineering and Bachelor of degree in Electrical Engineering (Electrical Power Engineering) from Universiti Teknologi Malaysia in 2003 and 2005. Currently, he is a Senior Lecturer in the Faculty of Electrical and Electronic Engineering, at Universiti Tun Hussien Onn (UTHM). He is a Professional Engineer (Ir.) registered with the board of Engineers Malaysia (BEM). He is also a corporate member of Institution of engineers Malaysia (IEM).His research interest include gas discharge, high voltage surge arresters as well as dielectric, and electrical insulation system.

Nur Farhani Ambo received her Bachelor's degree in Electrical Engineering (Industrial Power) from Universiti Teknikal Malaysia Melaka in 2016. She is currently pursuing her Master of Science degree in Electrical Engineering at Universiti Teknikal Malaysia Melaka. Her research interests include gas discharges, high voltage insulation systems and high voltage measurements. 


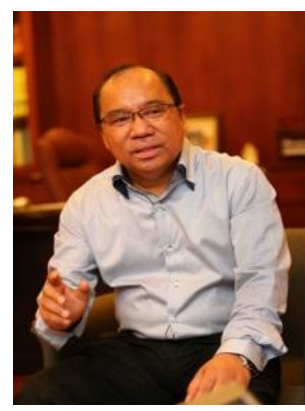

Jamaludin Mohd Wari is a Managing Director of Indkom Engineering Sdn Bhd, a medium voltage switchgear company base in Shah Alam, Selangor. He is a manager, designer and engineer with more than 25 years of experience in electrical power industry. His career path began in 1984 as an Engineer; became Manager in 1989 and later on in 1996 appointed as Managing Director. He had wide exposure and extensive experiences in high voltage distribution and transmission projects with highly engineered systems which require deep understanding of critical business drivers in multiple markets and industries. He led and motivated teams comprised of more than 200 employees and managed P\&L for business divisions exceeding RM100 million revenue.

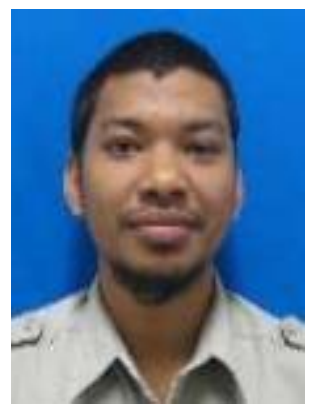

Imran Sutan Chairul received his Bachelor of Electrical Engineering (Industrial Power) from Universiti Teknikal Malaysia Melaka (UTeM) in 2008. In 2012, he received the Master of Electrical Engineering from Universiti Tenaga Nasional. Currently, he is a $\mathrm{PhD}$ candidate at Universiti Teknikal Malaysia Melaka (UTeM). His research interests include liquid and gas insulation as well as condition monitoring of power transformer. 